Aline Úrsula Rocha Fernandes ${ }^{(a)}$ Aline Portugal(b)

Letícia Rocha Veloso(b)

Marcelo Coelho Goiato(c)

Daniela Micheline dos Santos ${ }^{(d)}$

\begin{abstract}
(a) PhD student in Prosthodontics; (c) Adjunct Professor; (d) MSc student in Prosthodontics - Graduate Program in Dentistry, School of Dentistry of Araçatuba, São Paulo State University (UNESP), Araçatuba, SP, Brazil.

(b) DDS, University of Brasília (UnB), Brazil.
\end{abstract}

\section{Assessment of the flexural strength of two heat-curing acrylic resins for artificial eyes}

\begin{abstract}
Prosthetic eyes are artificial substitutes for the eyeball, made of heat-curing acrylic resin, serving to improve the esthetic appearance of the mutilated patient and his/her inclusion in society. The aim of this study was to assess the flexural strength of two heat-curing acrylic resins used for manufacturing prosthetic eyes. Thirty-six specimens measuring $64 \times 10 \times 3.3 \mathrm{~mm}$ were obtained and divided into four groups: acrylic resin for artificial sclera N1 (Artigos Odontológicos Clássico, São Paulo, SP, Brazil), heat-cure water technique (GI) and microwave-cured (GII); colorless acrylic resin for prosthetic eyes (Artigos Odontológicos Clássico, São Paulo, SP, Brazil), heat-cure water technique (GIII) and microwave-cured (GIV). Mechanical tests using three point loads were performed in a test machine (EMIC, São José dos Pinhais, PR, Brazil). The analysis of variance and the Tukey test were used to identify significant differences $(\mathrm{p}<0.01)$. Groups GII and GIV presented, respectively, the highest $(98.70 \pm 11.90 \mathrm{MPa})$ and lowest means $(71.07 \pm 8.93 \mathrm{MPa})$, with a statistically significant difference. The cure method used for the prosthetic eye resins did not interfere in their flexural strength. It was concluded that all the resins assessed presented sufficient flexural strength values to be recommended for the manufacture of prosthetic eyes.
\end{abstract}

Descriptors: Stress, mechanical; Artificial eye; Acrylic resins.
Corresponding author:

Aline Úrsula Rocha Fernandes SQN 209 B 602 Asa Norte

Brasília - DF - Brazil

CEP: 70854-020

E-mail: alineursula@bol.com.br 


\section{Introduction}

The goal of prosthetic eyes is to repair losses or deformities of the eyeball by using aloplastic material to recover facial esthetics, ${ }^{1,2}$ protect the anophthalmic cavity, restore the lachrymal direction, and prevent accumulation of this fluid in the cavity. ${ }^{3}$ The material used for fabricating prosthetic eyes must meet the necessary requirements in order to provide adequate adaptation and biocompatibility. It is important for professionals to understand the mechanical properties of the material in order for the prosthesis to be successfully made, inserted and used. ${ }^{1}$

The mechanical properties are defined by mechanical laws, that is, the physical science that deals with energy, forces and their effects on specimens. ${ }^{4}$ Flexural strength is a property that assures that the prosthesis will perform the functions for which it was designed in an adequate and safe manner, for a reasonable period of time. ${ }^{4}$ The ISO 1567 standard $(1999)^{5}$ indicates that the flexural strength for acrylic resins, either conventionally heat-cured in water or cured by microwave energy, must not be below $65 \mathrm{MPa}$.

Acrylic resins must be characterized in order to display an increased naturalness of prostheses. The addition of acrylic fibers or acrylic stains did not affect the flexural strength of a microwave-cured acrylic resin. ${ }^{6}$

Azzarri et al. ${ }^{7}$ (2003) affirmed that the curing processes of acrylic resins have been modified to improve the mechanical properties of these materials. Microwave energy offers advantages, such as a reduction in cure time and achievement of the plastic phase, greater homogeneity of the mixture and excellent prosthetic adaptation. ${ }^{7}$ The aim of this study was to assess the flexural strength of two acrylic resins used to obtain artificial eyes, as a function of curing.

\section{Material and Methods}

For this study, 36 specimens measuring $64 \times 10 \times 3.3 \mathrm{~mm}$ were manufactured ${ }^{5}$ and divided into four groups: acrylic resin for artificial sclera N1 (Artigos Odontológicos Clássico, São Paulo, SP, Brazil), heat-cured using the water technique (GI) or microwave-cured (GII); colorless acrylic resin for prosthetic eyes (Artigos Odontológicos Clássico, São Paulo, SP, Brazil), heat-cured using the water technique (GIII) or microwave-cured (GIV).

To obtain the acrylic resin specimens, bars of self-cured acrylic resin were made by means of a metal matrix. These bars were finished with abrasive papers of different grains $(320,400,600)$ (Norton, Guarulhos, SP, Brazil), in order to obtain the dimensions of $64 \times 10 \times 3.3 \mathrm{~mm}$, and have a uniform, smooth texture. Next, the bars were embedded in a fiberglass-reinforced plastic flask for microwaves (Artigos Odontológicos Clássico Ltda., São Paulo, SP, Brazil) and conventional metal flasks (JON Comércio de Produtos Odontológicos Ltda., São Paulo, SP, Brazil), using type III dental stone (Gesso-Rio, Rio Claro, SP, Brazil) in accordance with the manufacturer's standards. In order to enable the specimens to be removed from the molds more easily, the bars were embedded in laboratory silicone Zetalabor (Zhermack, Badia Polesine, RO, Italy). After removal of the bars from inside the flasks, the molds were filled with the resins assessed.

The resin for prosthetic eyes is similar to the heatcuring acrylic resin used for removable prostheses, according to the manufacturer's information. The formation of the copolymer results from the cure of the methylmethacrylate monomer, in suspension, by a chemical reaction. After this cure, it is ground and washed one more time than heat-cured water acrylic resin would be, providing a smaller granulation of the polymer particles. The conventional acrylic resin polymer is processed in a 60 mesh screen (threads per square inch), and for eyes, in an 80 mesh screen, forming grains of less than 130 microns. The pigmentation base of the resin for sclera is titanium dioxide, in an undeclared concentration, and another organic pigment at $0.2 \%$.

The acrylic resins of groups GI and GIII were manipulated in accordance with the manufacturer's instructions. The material was prepared with a polymer:monomer ratio of 3:1 by volume, and the plastic dough was packed into the flasks under a final packing pressure of $1,250 \mathrm{kgf}$. Twelve hours after final flask closure, the acrylic resin was cured in water at $74^{\circ} \mathrm{C}$ for $9 \mathrm{~h}$ in a thermo-curing unit ${ }^{8}$ (Solab Equipamentos para Laboratórios Ltda., Piracicaba, 
SP, Brazil).

The resins of groups GII and GIV were processed according to Fernandes ${ }^{1}$ (2004), using the monomer of the Onda Cryl resin (Artigos Odontológicos Clássico, SP, Brazil), in the proportion of 1 part of monomer to 3 of polymer, followed by three cure stages in a microwave, the first for 3 minutes at $30 \%$ of power, the second, for 4 minutes at $0 \%$, and the third, for 3 minutes at $60 \%$.

The acrylic resins were accommodated in molds, and the flasks were then kept in a hydraulic press (VH, Araraquara, SP, Brazil) under 1,200 kgf, kept at rest for twelve hours, and microwave-cured afterwards at 1,300 W (Microondas Panasonic Píccolo, São Paulo, SP, Brazil) or cured by immersion in hot water, according to the specimen group. After natural cooling of the flasks, they were opened and the acrylic resin specimens were removed.

The specimens were finished with abrasive papers nos. 320, 400, 600 and 1,200, simulating the laboratory conditions for making prosthetic eyes. The thickness, width and length of all specimens were checked with a pachymeter (ME-BA, Zagreb, Yugoslavia). Afterwards, the specimens were stored in water for $50 \pm 2$ hours at $37^{\circ} \mathrm{C}$, in order to hydrate them and to eliminate superficial monomers, ${ }^{5,9}$ so that the conditions of use would be similar to those of a prosthetic eye in the anophthalmic cavity.

After this procedure, flexural strength assessment was made by means of the module of rupture, with a constant speed of $5 \mathrm{~mm} / \mathrm{min}$., until fracture occurred. The specimens were placed in a holder with a distance of $50 \mathrm{~mm}$ between their margins, with a $100 \mathrm{~kg}$ load cell, in a EMIC DL 3000 Universal Test Machine (EMIC-DL 3000; EMIC Equip. Sist. de Ensaios Ltd., Curitiba, PR, Brazil), in accordance with the three-point technique. , $^{6,10,11}$

The values obtained were tabulated and submit- ted to the analysis of variance and the Tukey Test, at a level of significance of $1 \%$.

\section{Results}

The results obtained in this study have been described in Table 1 and Graph 1.

The statistical tests used demonstrated no statistical difference between the two cure methods assessed (hot water bath and microwave energy). However, the microwave-cured groups II and IV presented a statistically significant difference (Table 1, Graph 1). Groups GII and GIV presented, respectively, the highest $(98.70 \pm 11.90 \mathrm{MPa})$ and lowest means $(71.07 \pm 8.93 \mathrm{MPa})$, with statistical difference.

\section{Discussion}

Prosthetic eyes are used to treat patients that have suffered mutilation of the eyeball by trauma, disease or loss due to congenital factors. ${ }^{2,3}$ These prostheses are manufactured with heat-curing acrylic resin, employing white pigments, resulting in a color similar to that of the natural sclera; colorless heat-curing acrylic resin is used to cover the blood

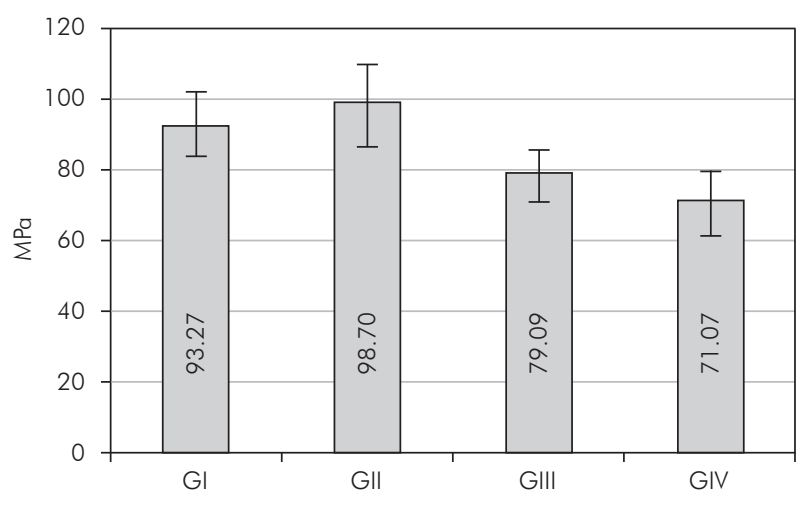

Graph 1 - Mean values and standard deviation of the flexural strength for the groups assessed.

Table 1 - Mean flexure strength values (MPa) of the specimens assessed, with varying resin and cure method (standard deviation in parentheses).

\begin{tabular}{c|c|c}
\hline Resins $\backslash$ methods & Heat-cured water & Microwave-cured \\
\hline Resin for sclera & $(G I)-93.27( \pm 8.23) a, A$ & $(G I I)-98.70( \pm 11.90) a, A$ \\
\hline Colorless resin & $(G I I)-79.09( \pm 7.39) a, A$ & $(G I V)-71.07( \pm 8.93) a, B$ \\
\hline
\end{tabular}

Means, followed by different lower case letters in the lines and capitals in the columns, differ statistically at the level of significance of $1 \%$ ( $p<0.01$ ). 
vessels and artificial iris, and to provide a similar shine to that of the natural eye.

Some authors $\mathrm{s}^{5-710-14}$ have taken the trouble to assess the mechanical properties of the acrylic resins for denture bases, by determining the masticatory forces to which they are submitted. In the present study, flexural strength of resins for fabricating prosthetic eyes was assessed based on the reports of patients, who relate frequent falling out of prosthetic eyes, whether during cleaning, or the procedures of inserting or removing them.

In this present study, no difference was found between the heat-curing resin when processed by the hot water bath and the heat-curing resin processed by microwave energy (Table 1). Ilbay et al. ${ }^{13}$ (1994) assessed the flexural strength of acrylic resins for complete dentures and found no difference between the cure methods of acrylic resins for complete dentures. Lai et al. ${ }^{14}$ (2004), however, reported slightly lower flexural strength values for resins polymerized by microwave-curing. In spite of their findings, the authors mentioned the advantage of using microwaves as providing uniform heating of the resin, i.e. the internal and external areas of the resin were submitted to the same temperature and this temperature was reached rapidly.

The acrylic resins for artificial sclera N1 (GI and GII), independently of the cure method, presented higher values of flexural strength, where the strength of group II was statistically higher than that of group IV (Table 1). It is possible that the association between the presence of pigments, a higher molecular weight, and microwave-curing, with more uniform heating, promoted stronger links among the polymeric chains, with a lower concentration of residual monomer. Studies on the interaction of these factors should be conducted in order to provide the manufacture of prostheses with increasingly enhanced mechanical characteristics.

With regard to cure method, the degree of conversion is the most important characteristic, as a consequence of the levels of residual monomers. ${ }^{12}$ These residual monomers may be non-reactive and have adverse effects on the physical and mechanical properties, ${ }^{9}$ as well as on biocompatibility. The residual monomer could result in tissue damage ${ }^{12}$ and diminish the hardness and flexural strength values. $^{15}$

The solubility of the residual monomer and water absorption could affect the polymer strength, acting as a plasticizer, diminishing the mechanical properties of the material, ${ }^{10}$ by reducing the forces between the polymeric chains. The greater organic load of the pigmented acrylic resin (for artificial sclera) would present less water absorption, resulting in greater flexural strength.

With regard to pigmentation, Silva et al. ${ }^{6}$ (2002) related that the addition of acrylic fibers or acrylic pigment in the proportions of $0.5 \%$ and $1.5 \%$ did not affect the flexural strength of acrylic resin microwave-cured in their study. The authors obtained mean flexural strength values of $86 \mathrm{MPa}$ for all the resins, with or without pigments. Due to the absence of literature on this subject, and the lack of knowledge regarding the total percentage of pigments added to the white acrylic resin for artificial sclera, the authors believe that the higher the quantity of pigments, the greater the flexural strength, due to the increase of the resin's molecular weight and generation of stronger polymeric chains.

The ISO 1567 standard $(1999)^{5}$ indicates that the flexural strength for acrylic resins, either conventionally activated by heat or microwave-cured, must not be below $65 \mathrm{MPa}$. In the present study, the flexure strength values found (Table 1) are above this value, indicating that all the groups assessed are satisfactory with regard to the studied property. For manufacturing prosthetic eyes, the resins for sclera and colorless resins are used in association.

Further studies are important to evaluate the mechanical properties of acrylic resins for prosthetic eyes, materials normally used in clinical practice.

\section{Conclusion}

Based on the results obtained, it may be concluded that:

- The cure method does not interfere in the property of flexural strength for the acrylic resins assessed.

- The GII showed statistically significant higher flexural strength values, when compared with the GIV. 


\section{References}

1. Fernandes AÚR. Evaluation of color stability in artificial iris painting for ocular prosthesis polymerized with microwaves, varying the color, the paint and the drying method [Thesis]. Araçatuba: Faculdade de Odontologia da Universidade Estadual Paulista; 2004.

2. Travieso MLA, Rivero AVA, Brito BOB. Rehabilitación ocular en niños. Investigaciones Medicoquirúrgicas. 2005 Jul;1:25-30.

3. Paranhos RMZF, Batalhão $\mathrm{CH}$, Semprini M, Regalo $\mathrm{SCH}$, Ito IY, Mattos MGC. Evaluation of ocular prosthesis biofilm and anophthalmic cavity contamination after use of three cleansing solutions. J Appl Oral Sci. 2007 Apr;15:33-8.

4. Anusavice KJ. Phillip's science of dental materials. $10^{\text {th }} \mathrm{ed}$. Philadelphia: WB Saunders Company; 1996.

5. International Organization for Standardization. ISO 1567:1999. Dentistry — denture base polymers [cited 2007 Aug 30]. Available from: http://www.iso.ch/iso/en/prodsservices/ISOstore/store.html.

6. Silva FAP, Silva TBP, Rached RN, Del Bel Cury AA. Effect of the intrinsic pigmentation on the flexural strength of a microwave-cured acrylic resin. Braz Dent J. 2002 May;13(3):2057.

7. Azzarri MJ, Cortizo MS, Alessandrini JL. Effect of the curing conditions on the properties of an acrylic denture base resin microwave-polymerised. J Dent. 2003 Sep;31(7):463-8.

8. Consani RL, Mesquita MF, Consani S, Correr Sobrinho L, Sousa-Neto MD. Effect of water storage on tooth dis- placement in maxillary complete dentures. Braz Dent J. 2006 May;17(1):53-7.

9. Smith DC, Bains ME. The detection and estimation of residual monomer in polymethyl methacrylate. J Dent Res. 1956 Feb;35(1):16-24.

10. Archadian N, Kawano F, Ohguri T, Ichikawa T, Matsumoto N. Flexural strength of rebased denture polymers. J Oral Rehabil. 2000 Aug;27(8):690-6.

11. Yunus N, Harrison A, Hugget R. Effect of microwave irradiation on the flexural strength and residual monomer levels of an acrylic resin repair material. J Oral Rehabil. 1994 Nov;21(6):641-8.

12. Austin AT, Basker RM. The level of residual monomer in acrylic denture base materials with particular reference to a modified method of analysis. Br Dent J. 1980 Nov;149(10):281-6.

13. Ilbay SG, Güvener S, Alkumru HN. Processing dentures using a microwave technique. J Oral Rehabil. 1994 Jan;21(1):1039.

14. Lai CP, Tsai MH, Chen M, Chang HS, Tay HH. Morphology and properties of denture acrylic resins cured by microwave energy and conventional water bath. Dent Mater. 2004 Feb;20(2):133-41.

15. Jagger RG. Effect of the curing cycle on some properties of a polymethylmethacrylate denture base material. J Oral Rehabil. 1978 Apr;5(2):151-7. 